\title{
Determinants of Bleeding Risk in Patients on Antithrombotic and Antifibrinolytic Drugs
}

\author{
Karina Meijer, M.D., Ph.D., ${ }^{1,2}$ and Sam Schulman, M.D., Ph.D. ${ }^{1}$
}

\section{ABSTRACT}

The risk of bleeding associated with antithrombotic and fibrinolytic therapy depends on factors that are specific for the drugs and the patients. In this narrative review, we describe the most important risk factors for bleeding for each class of drugs. Pertinent examples are recent initiation of therapy with vitamin $\mathrm{K}$ antagonists, low-molecular-weight heparins, and renal dysfunction, and higher dose of aspirin. However, for every class of drug, there are also examples that are more controversial. Knowledge of these risk factors helps to weigh the risk and benefit in the selection of therapy in individual patients. Moreover, some risk factors can be modified or avoided if they are recognized.

KEYWORDS: Anticoagulant, antifibrinolytic, antiplatelet, bleeding, complications

Early in his career, and long before the large trials in stroke and myocardial infarction, Dr. Eberhard Mammen wrote about the therapeutic possibilities of thrombolytic agents and their risk of causing bleeding. ${ }^{1}$ Twenty-four years later, he participated in a study addressing the timing of heparin administration in patients treated with streptokinase for acute myocardial infarction. ${ }^{2}$ That second study was published 22 years ago. This illustrates the length of Dr. Mammen's career. The width is illustrated by the fact that the text below contains references to his articles on bleeding with thrombolysis, with heparin, and with low-molecularweight heparin, but none of these were even within his main scope of work.

Any antithrombotic or fibrinolytic therapy increases the risk of bleeding, but the magnitude of the risk depends on factors that are specific for the drugs and the patients. To weigh the expected benefits against the bleeding risk of therapy for an individual patient, knowledge of these factors is necessary. Many studies have addressed factors that predict bleeding, but an important problem when comparing different studies is the variation in the definition of bleeding end points. The International Society on Thrombosis and Haemostasis has proposed a definition of major bleeding in nonsurgical patients, which should make future studies more comparable (Table 1). ${ }^{3}$

Below, we give a narrative review of the available data on the different classes of antithrombotic and fibrinolytic agents. We end with a review of the bleeding scores that have been developed to predict bleeding in specific clinical situations.

\section{VITAMIN K ANTAGONISTS}

Historically, target international normalized ratio (INR) and accordingly doses of vitamin $\mathrm{K}$ antagonists were higher than those we use today. For instance, in a 1969 article, Dr. Mammen quotes a starting dose of warfarin of 75 to $100 \mathrm{mg}$ and acenocoumarol of 25 to $50 \mathrm{mg}$ over the first 2 days of therapy. ${ }^{4}$ Subsequent studies have shown that more intensive therapy is a strong risk factor
${ }^{1}$ Thrombosis Service, McMaster Clinic, HHS-General Hospital, Hamilton, Ontario, Canada; ${ }^{2}$ Division of Haemostasis, Thrombosis and Rheology, Department of Haematology, University Medical Centre Groningen, Groningen, The Netherlands.

Address for correspondence and reprint requests: Sam Schulman, M.D., Ph.D., Thrombosis Service, HHS-General Hospital, 237 Barton St. E, Hamilton, ON L8L 2X2, Canada (e-mail: schulms@mcmaster.ca).

A Tribute to Eberhard F. Mammen, M.D. (1930-2008); Guest Editor, Emmanuel J. Favaloro, Ph.D., M.A.I.M.S.

Semin Thromb Hemost 2008;34:762-771. Copyright (C) 2008 by Thieme Medical Publishers, Inc., 333 Seventh Avenue, New York, NY 10001, USA. Tel: +1(212) 584-4662.

DOI 10.1055/s-0029-1145258. ISSN 0094-6176. 


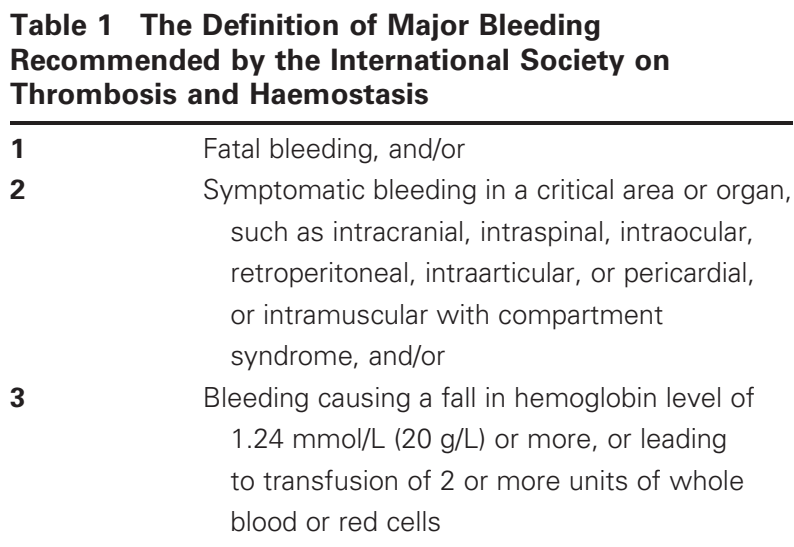

Source: Schulman S, Kearon C, on behalf of the Subcommittee on Control of Anticoagulation of the Scientific and Standardization Committee of the International Society on Thrombosis and Haemostasis. Definition of major bleeding in clinical investigations of antihemostatic medicinal products in non-surgical patients. Scientific and Standardization Communication. J Thromb Haemost 2005;3:692-694.

for bleeding. After valve surgery, higher targeted intensity increases the risk of bleeding. A randomized controlled trial (RCT) comparing the INR range of 2.5 to 3.5 and 3.5 to 4.5 in patients with mechanical valves reported annual major bleeding rates of $1.2 \%$ and $3.8 \%$, respectively. ${ }^{5}$ In a similar trial in patients during the first 3 months after tissue valve replacement, the bleeding rate was $4.6 \%$ and 0 with INR range of 2.5 to 4.0 and 2.0 to 2.25 , respectively. ${ }^{6}$ In contrast, target INR did not predict bleeding in two large cohort studies in patients with mixed indications for anticoagulation, whereas the actual intensity of anticoagulation was strongly associated with the risk of bleeding in both. ${ }^{7,8}$

Higher actual intensity is a strong risk factor for intracranial hemorrhage (ICH). A case-control study showed an odds ratio (OR) of 4.6 for $\mathrm{ICH}$ in patients with INR 3.5 to 3.9 compared with patients with INR 2.0 to $3.0 .{ }^{9}$ Variability of intensity was shown to be an independent predictor of bleeding. In a retrospective review, the relative risk (RR) of major bleeding was 1.6 $(p=0.003)$ in the patients in the highest versus the lowest tertile of INR variability, independent of the intensity of treatment. ${ }^{10}$

Recent initiation of warfarin treatment was identified as a risk factor for bleeding in several studies. The risk was highest in the first 3 months and continued to decrease during the first 2 years. ${ }^{8,10}$

Older age consistently increased the risk of bleeding and of ICH in a large number of studies. In a systematic review, the risk was approximately twofold in patients $>60$ to 75 years of age. ${ }^{11}$ Gender does not predict bleeding in most studies. Female gender did increase the risk of minor but not of major bleeding in a large cohort study. ${ }^{7}$

Several concomitant medical conditions have been studied as predictors of bleeding. Data are not consistent and depend on the prevalence of the concomitant condition in the patient group studied. For instance, in patients with peripheral artery disease, hypertension and diabetes increased the risk of bleeding. ${ }^{12}$ In a population-based cohort, malignancy was the only independent predictor of major bleeding. ${ }^{13}$ Other conditions implicated are cerebrovascular disease, serious heart disease, and renal insufficiency. ${ }^{14}$

Genetic variations in the cytochrome P450 CYP2C9 can influence the sensitivity for vitamin K antagonists. Carriership of the CYP2C $9^{*} 3$ allele was found to be associated with a history of bleeding $(\mathrm{OR}, 3.1){ }^{15}$

Adding $100 \mathrm{mg}$ aspirin to warfarin did not increase the risk of major bleeding in an RCT in patients after valve surgery, ${ }^{16}$ whereas it did in an otherwise similar study using $200 \mathrm{mg} .{ }^{17}$ The increase seen in this second study could be attributed to gastrointestinal bleeding. A direct comparison of adding 650 or $100 \mathrm{mg}$ aspirin to warfarin did not show an increase in the risk of major bleeding, but there was a trend toward more minor bleeding. ${ }^{18}$ Adding nonsteroidal anti-inflammatory drugs (NSAIDs) to warfarin increased the RR of upper gastrointestinal bleeding from 2.8 to 3.3 (compared with nonusers of warfarin) to 8.0 to 12.7 in two population-based cohorts. ${ }^{19,20} \mathrm{In}$ one of these cohorts, adding acetaminophen to warfarin increased the RR from 2.8 to $4.4 .^{20}$ These studies could not correct for confounding risk factors, like viral illnesses for which acetaminophen or NSAIDs were taken. Combination of selective serotonin reuptake inhibitors with warfarin did not increase the risk of intracranial or upper gastrointestinal bleeding in two case-control studies. ${ }^{21,22}$

\section{HEPARIN}

Intensity of heparin treatment was not a risk factor for bleeding in several smaller studies in acute venous thromboembolism (VTE). However, in a large study in acute coronary syndrome, the risk of major bleeding increased by $7 \%$ for every 10 -second increase in activated partial thromboplastin time (APTT). ${ }^{23}$

Intermittent intravenous administration of heparin is a risk factor for bleeding. In an RCT in patients with mixed indications for heparin, the rate of major bleeding was $8 \%$ in patients on an intermittent intravenous regimen according to APTT versus $1 \%$ in patients on continuous intravenous heparin. In patients on intermittent intravenous heparin without APTT measurements, the rate was $10 \%{ }^{24}$ In contrast, intermittent subcutaneous administration of heparin does not increase the risk of major bleeding compared with that of continuous intravenous, as shown in a meta-analysis of eight trials in acute VTE (RR, 0.79; 95\% confidence interval [CI], 0.42 to 1.48$).{ }^{25}$ 
The duration of heparin treatment in acute VTE did not influence the rate of major bleeding. ${ }^{26,27}$

Gender is debated as a risk factor: some authors do, but others do not, find an increased risk in women. ${ }^{28,29}$ Older age increases the risk of bleeding on heparin. In the initial treatment of acute VTE, the rate of major bleeding was $11.1 \%$ in patients over age 72 years (the median age in the study) versus $11.1 \%$ in those younger. ${ }^{30}$

Adding aspirin to heparin in patients undergoing coronary artery bypass grafting $(\mathrm{CABG})$ did increase the rate of reoperation for bleeding $(6.6 \%$ vs. $1.7 \%$, $p=0.002)$ but not the rate of bleeding unrelated to surgery $(4.5 \%$ vs. $5.0 \%){ }^{31}$ The addition of the glycoprotein IIb/IIIa receptor inhibitor (GPI) abciximab to a standard dose of heparin in patients undergoing percutaneous coronary intervention (PCI) did not increase the risk of major bleeding, although there was an increase in minor bleeding (3.5\% vs. $3.1 \%$, and $7.4 \%$ vs. $3.7 \%$, respectively). ${ }^{32}$

\section{LOW-MOLECULAR-WEIGHT HEPARIN}

In the initial studies of low-molecular-weight heparins, the incidence of bleeding was high. This was attributed to overdosing, as discussed by Dr. Mammen in $1990 .{ }^{33}$ More recently, data from a large registry confirmed that overdosing, as judged by body weight and renal function, increased the rate of major bleeding (OR, 1.47; $p$ $<0.001) .{ }^{34}$

Severe renal dysfunction is an important risk factor for bleeding on low-molecular-weight heparin (LMWH). Mostly, this is also explained by overdosing. A meta-analysis showed that with a standard therapeutic dose of enoxaparin, major bleeding occurred in $8.3 \%$ versus $2.4 \%$ of patients with creatinine clearance at or below $30 \mathrm{~mL} / \mathrm{min}$ and above $30 \mathrm{~mL} / \mathrm{min}$, respectively. When an adjusted dose of enoxaparin was given, major bleeding occurred in $0.9 \%$ versus $1.9 \% .{ }^{35}$ Milder renal dysfunction was also shown to be a risk factor for bleeding in a large study in acute coronary syndrome. Patients with creatinine clearances of $<58,58$ to 70,71 to 85 , and $>85 \mathrm{~mL} / \mathrm{min}$ had a major bleeding rate of $6.4 \%, 4.6 \%, 3.0 \%$, and $2.6 \%$, respectively, when given a standard dose of enoxaparin. ${ }^{36}$

Body weight did not predict bleeding in the initial treatment of deep vein thrombosis (DVT): major bleeding was seen in $1.2 \%$ and $0.9 \%$ of patients with a body weight below and above $100 \mathrm{~kg}$, respectively. ${ }^{37}$

Advanced age is often cited as a predictor of bleeding, but data are scarce. In a retrospective chart review, age was an independent risk factor for bleeding (OR 2.6 for every 10-year increment; $p=0.039$ ). ${ }^{38}$

Once- versus twice-daily administration of LMWH did not increase the rate of bleeding in the initial treatment of VTE: a meta-analysis reported an incidence of $2.2 \%$ versus $2.9 \%$ (OR, 0.77$).{ }^{39}$ The timing of the start of LMWH for prophylaxis in elective hip surgery predicts for bleeding. A meta-analysis found no increased risk of bleeding in starting 12 hours preoperatively compared with 12 hours postoperatively (1.4\% vs. $2.5 \%$ major bleeding, respectively), but the incidence was higher (6.3\%) when LMWH was started either less than 12 hours before or less than 12 hours after surgery. ${ }^{40}$

Different preparations of LMWH have not been compared directly for rates of bleeding. An analysis of the available data did not indicate a clear difference, except for a possible lower bleeding rate for dalteparin. ${ }^{41}$

In the retrospective chart review mentioned above, adding clopidogrel to LMWH increased the risk of bleeding (OR, 7.7; $p=0.034)$ but adding aspirin did not. ${ }^{38}$

\section{FONDAPARINUX}

Age over 65 years increased the risk of major bleeding on fondaparinux in patients with acute coronary syndromes ( $2.7 \%$ vs. $1.4 \%$ in younger patients), whereas gender did not predict for bleeding $(2.0 \%$ in men vs. $2.5 \%$ in women). ${ }^{42}$ A subsequent analysis from the same trial showed an increasing risk of bleeding with decreasing renal function, although less than with the comparator LMWH $(2.8 \%, 2.5 \%, 2.9 \%$, and $1.6 \%$ with glomerular filtration rate [GFR] $<58,58$ to 70,71 to 85 , and $>85 \mathrm{~mL} / \mathrm{min}$, respectively). ${ }^{36}$

Shorter time between major orthopedic surgery and the postoperative start of prophylactic fondaparinux significantly increased the risk of major and overt bleeding in a meta-analysis of four trials. ${ }^{43}$

Obesity protected against major bleeding in patients treated with fondaparinux for acute VTE ( $0.3 \%$ vs. $1.5 \%$ in body mass index $\left.<30 \mathrm{~kg} / \mathrm{m}^{2}\right)^{44}$

\section{ASPIRIN}

Surprisingly, not much is published on patient factors that predict bleeding on aspirin. Available data are mainly derived from subgroups within the active arm of large cardiovascular trials. A meta-analysis of RCTs addressing the use of aspirin in the primary prevention of cardiovascular disease showed no difference in major bleeding between men and women (OR vs. placebo 1.72 and 1.68 , respectively). ${ }^{45}$ Gender and blood pressure did not predict for bleeding in a combined report of two large trials of aspirin in the first 2 to 4 weeks after ischemic stroke, whereas older age had no effect on the risk of hemorrhagic stroke but did seem to increase the risk of major extracranial bleeding (absolute risk of $0.5 \%$, $1.1 \%$, and $1.6 \%$ in patients $<65,65$ to 74 and $>74$ years, respectively). Of note, a proportion of patients in this report also used heparin. ${ }^{46}$ In a small trial, patients carrying the GPIIb/IIIa $\mathrm{Pl}_{\mathrm{A} 2}$ allele $\mathrm{A}$ showed an increase 
of blood loss during CABG when they were pretreated with aspirin. ${ }^{47}$

A larger dose of aspirin clearly increases the risk of bleeding: in a meta-analysis of long-term use of aspirin, the risk of all bleeds was increased from $3.7 \%$ to 9.8 to $11.3 \%$ with doses $>100 \mathrm{mg}$ daily. The relative risk was highest for gastrointestinal bleeding, but it was also significantly higher for categories of fatal, major, and minor bleeding. ${ }^{48}$ Meta-analyses of studies comparing regular and enteric-coated or modified-release aspirin did not show a difference in risk of gastrointestinal bleeding. ${ }^{49,50}$

Adding warfarin (target INR, 2 to 3 ) to aspirin after acute coronary syndromes increased the risk of major bleeding, as shown in a meta-analysis (OR, 2.3). ${ }^{51}$ The addition of long-term clopidogrel to aspirin also increases the risk, but to a lesser extent $(\mathrm{OR}, 1.8) .^{52}$ In the same meta-analysis, short-term treatment with clopidogrel did not increase bleeding risk. Lastly, the addition of selective serotonin reuptake inhibitors to aspirin did not seem to increase the risk of $\mathrm{ICH}$ in a recent case-control study. ${ }^{21}$

\section{CLOPIDOGREL}

Although clopidogrel was tested as a single antiplatelet drug (versus aspirin) in a large number of patients, no reports have been published on patient characteristics that could predict bleeding in this setting. Available data are from studies in which all patients were also on aspirin. Mild to moderate renal dysfunction did not increase the risk of any bleeding ( $R R$ vs. placebo 1.2, 1.3 , and 1.1 for no, mild, and moderate renal dysfunction, respectively) in an analysis from the CREDO trial, in patients on clopidogrel followed for 1 year after elective PCI. ${ }^{53}$ In another analysis from the same trial, higher body mass index (BMI) protected against bleeding $(13 \%$ reduction in any bleeding for every 5 units increase in BMI). ${ }^{54}$ Increasing the loading dose of clopidogrel before PCI to more than $300 \mathrm{mg}$ did not increase the risk of bleeding, as shown by a metaanalysis, but it must be noted that the number of events of major bleeding was small (OR 1.88 and 0.99 vs. placebo for major and minor bleeding, respectively). ${ }^{55}$

The addition of aspirin to clopidogrel for secondary prophylaxis after stroke or transient ischemic attack (TIA) clearly increases the risk of bleeding: life-threatening bleeds occurred in $2.6 \%$ versus $1.3 \%$ during 18 month follow-up in the MATCH trial. ${ }^{56}$

\section{GLYCOPROTEIN IIb/IIIa RECEPTOR INHIBITORS}

Several studies and meta-analyses have been published on the predictors of bleeding in GPI therapy. All studies have been performed in acute coronary syndromes, and
GPI was used on top of standard anticoagulant and antiplatelet therapy.

Old age is a risk factor for bleeding: a recent, large meta-analysis reported that the OR of bleeding versus placebo was $1.9,1.9,1.6$, and 2.5 in patients $<60,60$ to 69,70 to 79 , and $>79$ years, respectively. ${ }^{57}$ The difference in absolute bleeding risk on GPI between the youngest and the oldest patients was much larger $(1.5 \%$ vs. $5.7 \%)$, reflecting increased baseline risk and risk of standard therapy.

Data on the role of gender as a risk factor for bleeding on GPI is not consistent. With or without the drug, women have a higher risk of bleeding than do men in the setting of acute coronary syndrome. ${ }^{58,59} \mathrm{~A}$ meta-analysis showed no increased bleeding risk on abciximab compared with placebo in women $(3.0 \%$ and $2.9 \%$ major bleeding, respectively). ${ }^{58}$ Analysis of data from a large registry showed, however, a larger increase of major bleeding for women than for men (15.7\% and $8.5 \%$ on abciximab vs. $7.3 \%$ and $5.4 \%$ on placebo, respectively). ${ }^{59}$

Decreased renal function was an independent predictor of bleeding in a relatively small observational study on eptifibatide (OR 6 to 9, depending on the definition of bleeding) ${ }^{60}$ Another study on the same drug found that the predictive value of renal function could mainly be explained by older age. ${ }^{61}$ The effects of age, gender, and renal function could partly be explained from their role as risk factors for overdosing, which significantly increased the risk of bleeding in a large registry $(\mathrm{OR}, 1.36) .^{62}$

Adding clopidogrel pretreatment to GPI did not increase the risk of bleeding, as shown in a metaanalysis. $^{63}$ Different GPIs can have different risks of bleeding, as shown in a comparison between tirofiban and abciximab (total bleeding $2.9 \%$ vs. $5.0 \%$, respectively). ${ }^{64}$

\section{THROMBOLYTIC THERAPY}

In both stroke and myocardial infarction, the most important bleeding complication is hemorrhagic stroke. However, the risk factors for bleeding depend strongly on the indication for thrombolytic therapy. Apart from differences in research interests between neurologists and cardiologists and real differences in patient groups, patients treated for stroke have a much higher background incidence of $\mathrm{ICH}$ than that of patients treated for myocardial infarction.

In stroke, the most consistent risk factor reported in RCTs is larger neurologic deficit. ${ }^{65,66}$ Older age was a risk factor in one of these trials (OR 1.3 for every 10 years ${ }^{66}$ but not in the other nor in a retrospective series. ${ }^{65,67}$

Diabetes was reported as an independent risk factor (OR, 3.7; $p<0.001) .{ }^{68}$ Coagulation parameters 
on admission did not predict for symptomatic bleeding. ${ }^{69}$

Early ischemic changes seen on computed tomography $(\mathrm{CT})$ were associated with bleeding in several studies, with OR 3 to $3.5 .{ }^{66,68}$ Leukoaraiosis seen on magnetic resonance imaging was an independent risk factor for bleeding in another study (OR, 2.9; $p=0.03)^{67}$

A higher dose of a thrombolytic agent increased the risk of fatal $\mathrm{ICH}(\mathrm{OR}, 3.25)$, but not the risk of any intracranial bleeding (OR, 1.54; not statistically significant), as shown in a meta-analysis. ${ }^{70}$ In the same analysis, there were no statistically significant differences in the rate of $\mathrm{ICH}$ between different thrombolytic agents, but the number of events was very small.

In myocardial infarction, the GUSTO-I trial (41,000 patients) and the NRMI-2 registry (71,000 patients) have reported on risk factors for $\mathrm{ICH}^{71,72}$ Older age, lower body weight, prior stroke, and higher diastolic or systolic blood pressure were independent predictors in both studies. Female gender was an independent risk factor in the registry, but not in the trial. In contrast, female gender was reported as a strong independent risk factor in another trial $(p=2.90){ }^{73}$ Black ethnicity was also an independent risk factor in the registry, whereas it was not reported in GUSTO-1.

In a case-control study based on several trials and a registry in myocardial infarction, 150 patients with $\mathrm{ICH}$ were included. Independent risk factors were age over 65 years $(\mathrm{OR}, 2.2)$, body weight less than $70 \mathrm{~kg}$ $(\mathrm{OR}, 2.1)$, and hypertension $(\mathrm{OR}, 2.0)^{74}$

Risk factors for all types of bleeding have also been reported from the GUSTO-I trial. ${ }^{75}$ As for ICH, older age and lower body weight were risk factors. Additionally, female gender, black ethnicity, and treatment in the United States were found to be independent risk factors for any bleeding.

Streptokinase and tissue plasminogen activator (tPA) were directly compared in three large RCTs. In two, tPA was associated with a modest increase in the risk of $\mathrm{ICH}(0.3 \%$ vs. $0.25 \%$, and $0.70 \%$ vs. $0.57 \%$, respectively). ${ }^{72,76}$ In the third, the difference was much larger ( $0.66 \%$ for $\mathrm{tPA}$ vs. $0.24 \%$ for streptokinase). ${ }^{77}$

A higher dose of tPA is clearly associated with an increased risk of intracranial bleeding. In a dose-finding study, the risk was $1.3 \%$ and $0.4 \%$ for 150 and $100 \mathrm{mg}$, respectively. ${ }^{78}$ In the NRMI-2 registry, a dose of $1.5 \mathrm{mg} /$ $\mathrm{kg}$ body weight was an independent predictor of $\mathrm{ICH}$ (OR, 1.49). ${ }^{71}$ A higher dose of tenecteplase was associated with an increased risk of $\mathrm{ICH}$ in one trial $(3.8 \%$, $1.9 \%$, and $1.0 \%$ for 50,40 , and $30 \mathrm{mg}$, respectively), but not in a parallel, larger trial $(0.62 \%$ and $0.94 \%$ for 40 and $30 \mathrm{mg}$, respectively). ${ }^{79,80}$

Adding aspirin to thrombolytic therapy did not increase the risk of major bleeding in the ISIS-2 trial, however the number of cases of ICH was too small for a reliable comparison. ${ }^{81}$ The addition of GPI to thrombolytic therapy was evaluated in a meta-analysis, and the risk of major bleeding increased by $69 \%$ (95\% CI, 38 to 109\%). ${ }^{82}$

Combination of heparin with thrombolytic therapy increased the risk of $\mathrm{ICH}$ in one large trial $(0.56 \%$ vs. $0.40 \%, p<0.05)$ but not in the other $(0.3 \%$ vs. $0.3 \%){ }^{76,77}$ Both showed a modest increase in total bleeding ( $1.0 \%$ vs. $0.8 \%$ and $1.0 \%$ vs. $0.6 \%$, respectively). A study in which Dr. Mammen was involved showed that the timing of adding heparin to thrombolytic therapy matters: the risk of bleeding was decreased in patients who received heparin 12 hours after intracoronary streptokinase compared with that of historical controls who received heparin immediately after streptokinase ( 0 vs. $5.6 \%$ major bleeding). ${ }^{2}$

\section{BLEEDING PREDICTION MODELS}

To facilitate the clinical use of the different risk factors for bleeding, formal bleeding scores have been developed. Most of them were developed for vitamin K antagonists, either in inpatients starting anticoagulation or in outpatients. Table 2 outlines the available scores. In outpatients, the Outpatient Bleeding Risk Index (OBRI) by Landefeld and Beyth is the best-validated score and is easy to use. ${ }^{83}$ The newer scores are not yet validated by others and are more complicated, using more variables. ${ }^{84,85}$ The score by Shireman et $\mathrm{al}^{84}$ requires calculation. The available scores regarding inpatients are from the years when use of intravenous heparin was standard and were not valid when used by other groups. ${ }^{86,87}$

\section{CONCLUSION}

The risks of bleeding on antithrombotic or fibrinolytic drugs differ between patients and circumstances. Dr. Eberhard Mammen provided an insight into this area of work long before the large trials in stroke and myocardial infarction. For vitamin K antagonists, recent initiation of therapy, higher actual intensity, variability of intensity, and older patient age clearly increase the risk of bleeding. In the case of heparin, undisputed risk factors are also older age and the practice of giving intermittent intravenous doses. Overdosing, especially in patients with impaired renal function, is the main recognized risk factor for bleeding on LMWH. Impaired renal function and older age are also risk factors for bleeding on fondaparinux. For aspirin, increasing the dose above $100 \mathrm{mg}$ once daily and adding warfarin are undisputed risk factors for bleeding. As for clopidogrel, adding aspirin increases the risk of bleeding. Overdosing, older age, and impaired renal function are risk factors for bleeding on GPI. In stroke, larger neurologic deficit is the main predictor of bleeding on thrombolytic therapy. 
Table 2 Bleeding Scores for Prediction of Risk of Bleeding on Anticoagulant Therapy

\begin{tabular}{|c|c|c|c|}
\hline Authors & Category & Components & Validation by Others \\
\hline \multirow[t]{4}{*}{$\begin{array}{l}\text { Landefeld and Goldman, }{ }^{88} \\
\text { modified by Beyth et al }\end{array}$} & $\begin{array}{l}\text { Outpatients, new on } \\
\text { warfarin, mixed indications }\end{array}$ & Age $\geq 65$ years & Yes $^{84,85,89,90}$ \\
\hline & & Prior gastrointestinal bleeding & \\
\hline & & Prior stroke & \\
\hline & & $\begin{array}{l}\text { Recent myocardial infarction/renal } \\
\text { dysfunction/anemia/diabetes }\end{array}$ & \\
\hline \multirow[t]{3}{*}{ Kuijer et al ${ }^{91}$} & Outpatients, VTE & Age $\geq 60$ years & Yes $^{84,85}$ \\
\hline & & Female gender & \\
\hline & & Malignancy & \\
\hline \multirow[t]{8}{*}{ Shireman et $\mathrm{al}^{84}$} & $\begin{array}{l}\text { Outpatients, atrial } \\
\text { fibrillation }\end{array}$ & Age $\geq 70$ years & No \\
\hline & & Female gender & \\
\hline & & Remote prior bleeding & \\
\hline & & Recent prior bleeding & \\
\hline & & Alcohol/drugs & \\
\hline & & Diabetes & \\
\hline & & Anemia & \\
\hline & & Antiplatelet drug & \\
\hline \multirow[t]{11}{*}{ Gage et $a^{85}$} & $\begin{array}{l}\text { Outpatients, atrial } \\
\text { fibrillation }\end{array}$ & Hepatic/renal disease & No \\
\hline & & Alcohol & \\
\hline & & Malignancy & \\
\hline & & Age $>75$ years & \\
\hline & & Thrombocytopenia/thrombocytopathy & \\
\hline & & Prior bleeding & \\
\hline & & Hypertension & \\
\hline & & Anemia & \\
\hline & & CYP 2C9 variants & \\
\hline & & Fall risk & \\
\hline & & Stroke & \\
\hline \multirow[t]{4}{*}{ Landefeld et al ${ }^{86,92}$} & $\begin{array}{l}\text { Inpatients, mixed } \\
\text { indications }\end{array}$ & $\begin{array}{l}\text { Number of specified comorbid conditions } \\
\text { (cardiac/renal/liver dysfunction, } \\
\text { malignancy, anemia) }\end{array}$ & $\begin{array}{l}\text { Score did not } \\
\text { predict bleeding }^{87}\end{array}$ \\
\hline & & Intravenous heparin in older patients & \\
\hline & & Prothrombin time (PT)/APTT $>2 \times$ control & \\
\hline & & Increasing bilirubin during therapy & \\
\hline \multirow[t]{4}{*}{ Nieuwenhuis et al ${ }^{87}$} & Inpatients, VTE & $\begin{array}{l}\text { World Health Organization (WHO) } \\
\quad \text { performance score } \geq 2\end{array}$ & $\begin{array}{l}\text { Score did not } \\
\text { predict bleeding }\end{array}$ \\
\hline & & Prior bleeding & \\
\hline & & Recent trauma/surgery & \\
\hline & & Body surface area $<2 \mathrm{~m}^{2}$ & \\
\hline
\end{tabular}

In myocardial infarction, older age, overdosing (or the proxy lower body weight), and adding GPI are the main recognized risk factors for bleeding.

Some risk factors, for instance renal dysfunction and older age, are not modifiable. They should be taken into account when weighing the benefits of therapy against the risks. Others might, in addition to increasing risk, also increase benefit and thus have a net positive balance. Combinations of drugs but also older age can fall into this category. Finally, some risk factors are avoidable when they are recognized such as selection of anticoagulants that are not eliminated by the kidneys in patients with renal impairment or discontinuation of platelet inhibitors if not clearly indicated in patients starting on a vitamin $\mathrm{K}$ antagonist. All efforts should be made to improve the quality of anticoagulation management (e.g., by dosing with computer software or nomograms to increase the time in therapeutic range). Self-testing and self-management for motivated patients on vitamin $\mathrm{K}$ antagonists will also reduce the risk of 
complications. Routine calculation of the creatinine clearance before starting treatment with LMWH or fondaparinux with appropriate choice of dose and agent is crucial to minimize bleeding risk. Knowledge of these important risk factors is mandatory to make one of the most complicated treatments safer.

\section{REFERENCES}

1. Mammen E. El tratamiento de las tromboembolias. Folia Clin Int (Barc) 1962;12:146-154

2. Timmis GC, Mammen EF, Ramos RG, et al. Hemorrhage vs rethrombosis after thrombolysis for acute myocardial infarction. Arch Intern Med 1986;146:667-672

3. Schulman S, Kearon Con behalf of the Subcommittee on Control of Anticoagulation of the Scientific and Standardization Committee of the International Society on Thrombosis and Haemostasis. Definition of major bleeding in clinical investigations of antihemostatic medicinal products in non-surgical patients. Scientific and Standardization Communication. J Thromb Haemost 2005;3:692-694

4. Mammen EF. Grundlagen der Anticoagulantien-Behandlung. Internist (Berlin) 1969;10:2-8

5. Pengo V, Barbero F, Banzato A, et al. A comparison of a moderate with a moderate-high intensity oral anticoagulant treatment in patients with mechanical heart valve prostheses. Thromb Haemost 1997;77:839-844

6. Turpie AG, Gunstensen J, Hirsh J, Nelson H, Gent M. Randomised comparison of two intensities of oral anticoagulant therapy after tissue heart valve replacement. Lancet 1988;1:1242-1245

7. Van der Meer FJ, Rosendaal FR, Vandenbroucke JP, Briët E. Bleeding complications in oral anticoagulant therapy. An analysis of risk factors. Arch Intern Med 1993;153:15571562

8. Palareti G, Leali N, Coccheri S, et al. Bleeding complications of oral anticoagulant treatment: an inception-cohort, prospective collaborative study (ISCOAT). Italian Study on Complications of Oral Anticoagulant Therapy. Lancet 1996; 348:423-428

9. Fang MC, Chang Y, Hylek EM, et al. Advanced age, anticoagulation intensity, and risk for intracranial hemorrhage among patients taking warfarin for atrial fibrillation. Ann Intern Med 2004;141:745-752

10. Fihn SD, McDonell M, Martin D, et al. Risk factors for complications of chronic anticoagulation. A multicenter study. Warfarin Optimized Outpatient Follow-up Study Group. Ann Intern Med 1993;118:511-520

11. Hutten BA, Lensing AW, Kraaijenhagen RA, Prins MH. Safety of treatment with oral anticoagulants in the elderly. A systematic review. Drugs Aging 1999;14:303-312

12. Ariesen MJ, Tangelder MJ, Lawson AJ, Eikelboom BC, Grobbee DE, Algra A. Dutch Bypass Oral Anticoagulants or Aspirin Study Group. Risk of major haemorrhage in patients after infrainguinal venous bypass surgery: therapeutic consequences? The Dutch BOA (Bypass Oral Anticoagulants or Aspirin) Study. Eur J Vasc Endovasc Surg 2005;30:154-159

13. Gitter MJ, Jaeger TM, Petterson TM, Gersh BJ, Silverstein MD. Bleeding and thromboembolism during anticoagulant therapy: a population-based study in Rochester, Minnesota. Mayo Clin Proc 1995;70:725-733
14. Schulman S, Beyth RJ, Kearon C, Levine MN. American College of Chest Physicians. Hemorrhagic complications of anticoagulant and thrombolytic treatment: American College of Chest Physicians Evidence-Based Clinical Practice Guidelines (8th Edition). Chest 2008;133:257S-298S

15. Hummers-Pradier E, Hess S, Adham IM, Papke T, Pieske B, Kochen MM. Determination of bleeding risk using genetic markers in patients taking phenprocoumon. Eur J Clin Pharmacol 2003;59:213-219

16. Turpie AG, Gent M, Laupacis A, et al. A comparison of aspirin with placebo in patients treated with warfarin after heart-valve replacement. N Engl J Med 1993;329:524-529

17. Laffort $P$, Roudaut $R$, Roques $X$, et al. Early and long-term (one-year) effects of the association of aspirin and oral anticoagulant on thrombi and morbidity after replacement of the mitral valve with the St. Jude medical prosthesis: a clinical and transesophageal echocardiographic study. J Am Coll Cardiol 2000;35:739-746

18. Altman R, Rouvier J, Gurfinkel E, Scazziota A, Turpie AG. Comparison of high-dose with low-dose aspirin in patients with mechanical heart valve replacement treated with oral anticoagulant. Circulation 1996;94:2113-2116

19. Shorr RI, Ray WA, Daugherty JR, Griffin MR. Concurrent use of nonsteroidal anti-inflammatory drugs and oral anticoagulants places elderly persons at high risk for hemorrhagic peptic ulcer disease. Arch Intern Med 1993;153:1665-1670

20. Johnsen SP, Sørensen HT, Mellemkjaer L, et al. Hospitalisation for upper gastrointestinal bleeding associated with use of oral anticoagulants. Thromb Haemost 2001;86:563-568

21. Kharofa J, Sekar P, Haverbusch M, et al. Selective serotonin reuptake inhibitors and risk of hemorrhagic stroke. Stroke 2007;38:3049-3051

22. Kurdyak PA, Juurlink DN, Kopp A, Herrmann N, Mamdani MM. Antidepressants, warfarin, and the risk of hemorrhage. J Clin Psychopharmacol 2005;25:561-564

23. Anand SS, Yusuf S, Pogue J, Ginsberg JS, Hirsh J. Organization to Assess Strategies for Ischemic Syndromes Investigators. Relationship of activated partial thromboplastin time to coronary events and bleeding in patients with acute coronary syndromes who receive heparin. Circulation 2003;107:2884-2888

24. Salzman WE, Deykin D, Shapiro RM, Rosenberg R. Management of heparin therapy: controlled prospective study. N Engl J Med 1975;292:1046-1050

25. Hommes DW, Bura A, Mazzolai L, Büller HR, Ten Cate JW. Subcutaneous heparin compared with continuous intravenous heparin administration in the initial treatment of deep vein thrombosis. A meta-analysis. Ann Intern Med 1992; 116:279-284

26. Gallus A, Jackaman J, Tillett J, Mills W, Wycherley A. Safety and efficacy of warfarin started early after submassive venous thrombosis or pulmonary embolism. Lancet 1986;2: 1293-1296

27. Hull RD, Raskob GE, Rosenbloom D, et al. Heparin for 5 days as compared with 10 days in the initial treatment of proximal venous thrombosis. N Engl J Med 1990;322: $1260-1264$

28. Jick H, Slone D, Borda IT, Shapiro S. Efficacy and toxicity of heparin in relation to age and sex. N Engl J Med 1968; 279:284-286

29. Glazier RL, Crowell EB. Randomized prospective trial of continuous vs intermittent heparin therapy. JAMA 1976;236: 1365-1367 
30. Campbell NR, Hull RD, Brant R, Hogan DB, Pineo GF, Raskob GE. Aging and heparin-induced bleeding. Arch Intern Med 1996;156:857-860

31. Sethi GK, Copeland JG, Goldman S, Moritz T, Zadina K, Henderson WG. Implications of preoperative administration of aspirin in patients undergoing coronary artery bypass grafting. Department of Veterans Affairs Cooperative Study on Antiplatelet Therapy. J Am Coll Cardiol 1990;15:15-20

32. The EPILOG Investigators. Platelet glycoprotein IIb/IIIa receptor blockade and low-dose heparin during percutaneous coronary revascularization. N Engl J Med 1997;336:16891696

33. Mammen EF. Why low molecular weight heparin? Semin Thromb Hemost 1990;16(Suppl):1-4

34. LaPointe NM, Chen AY, Alexander KP, et al. Enoxaparin dosing and associated risk of in-hospital bleeding and death in patients with non ST-segment elevation acute coronary syndrome. Arch Intern Med 2007;167:1539-1544

35. Lim W, Dentali F, Eikelboom JW, Crowther MA. Metaanalysis: low-molecular-weight heparin and bleeding in patients with severe renal insufficiency. Ann Intern Med 2006;144:673-684

36. Fox KA, Bassand JP, Mehta SR, et al. Influence of renal function on the efficacy and safety of fondaparinux relative to enoxaparin in non ST-segment elevation acute coronary syndromes. Ann Intern Med 2007;147:304-310

37. Büller HR, Davidson BL, Decousus H, et al. Fondaparinux or enoxaparin for the initial treatment of symptomatic deep venous thrombosis: a randomized trial. Ann Intern Med 2004;140:867-873

38. Macie C, Forbes L, Foster GA, Douketis JD. Dosing practices and risk factors for bleeding in patients receiving enoxaparin for the treatment of an acute coronary syndrome. Chest 2004;125:1616-1621

39. Van Dongen CJ, MacGillavry MR, Prins MH. Once versus twice daily LMWH for the initial treatment of venous thromboembolism. Cochrane Database Syst Rev 2005;3: CD003074

40. Strebel N, Prins M, Agnelli G, Büller HR. Preoperative or postoperative start of prophylaxis for venous thromboembolism with low-molecular-weight heparin in elective hip surgery? Arch Intern Med 2002;162:1451-1456

41. Van der Heijden JF, Prins MH, Büller HR. For the initial treatment of venous thromboembolism: are all low-molecular-weight heparin compounds the same? Thromb Res 2000;100:V121-V130

42. Yusuf S, Mehta SR, Chrolavicius S, et al. Comparison of fondaparinux and enoxaparin in acute coronary syndromes. N Engl J Med 2006;354:1464-1476

43. Turpie AG, Bauer KA, Eriksson BI, Lassen MR. Fondaparinux vs enoxaparin for the prevention of venous thromboembolism in major orthopedic surgery: a meta-analysis of 4 randomized double-blind studies. Arch Intern Med 2002; 162:1833-1840

44. Davidson BL, Büller HR, Decousus H, et al. Effect of obesity on outcomes after fondaparinux, enoxaparin, or heparin treatment for acute venous thromboembolism in the Matisse trials. J Thromb Haemost 2007;5:1191-1194

45. Berger JS, Roncaglioni MC, Avanzini F, Pangrazzi I, Tognoni G, Brown DL. Aspirin for the primary prevention of cardiovascular events in women and men: a sex-specific meta-analysis of randomized controlled trials. JAMA 2006; 295:306-313
46. Chen ZM, Sandercock P, Pan HC, et al. Indications for early aspirin use in acute ischemic stroke: a combined analysis of 40000 randomized patients from the Chinese acute stroke trial and the international stroke trial. On behalf of the CAST and IST collaborative groups. Stroke 2000;31:1240-1249

47. Morawski W, Sanak M, Cisowski M, et al. Prediction of the excessive perioperative bleeding in patients undergoing coronary artery bypass grafting: role of aspirin and platelet glycoprotein IIIa polymorphism. J Thorac Cardiovasc Surg 2005;130:791-796

48. Serebruany VL, Steinhubl SR, Berger PB, et al. Analysis of risk of bleeding complications after different doses of aspirin in 192,036 patients enrolled in 31 randomized controlled trials. Am J Cardiol 2005;95:1218-1222

49. Walker J, Robinson J, Stewart J, Jacob S. Does enteric-coated aspirin result in a lower incidence of gastrointestinal complications compared to normal aspirin?. Interact Cardiovasc Thorac Surg 2007;6:519-522

50. Derry S, Loke YK. Risk of gastrointestinal haemorrhage with long term use of aspirin: meta-analysis. BMJ 2000;321:11831187

51. Andreotti F, Testa L, Biondi-Zoccai GG, Crea F. Aspirin plus warfarin compared to aspirin alone after acute coronary syndromes: an updated and comprehensive meta-analysis of 25,307 patients. Eur Heart J 2006;27:519-526

52. Bowry AD, Brookhart MA, Choudhry NK. Meta-analysis of the efficacy and safety of clopidogrel plus aspirin as compared to antiplatelet monotherapy for the prevention of vascular events. Am J Cardiol 2008;101:960-966

53. Best PJ, Steinhubl SR, Berger PB, et al. The efficacy and safety of short- and long-term dual antiplatelet therapy in patients with mild or moderate chronic kidney disease: results from the Clopidogrel for the Reduction of Events During Observation (CREDO) trial. Am Heart J 2008;155:687-693

54. Kelly RV, Hsu A, Topol E, Steinhubl S. The influence of body mass index on outcomes and the benefit of antiplatelet therapy following percutaneous coronary intervention. J Invasive Cardiol 2006;18:115-119

55. Lotrionte M, Biondi-Zoccai GG, Agostoni P, et al. Metaanalysis appraising high clopidogrel loading in patients undergoing percutaneous coronary intervention. Am J Cardiol 2007;100:1199-1206

56. Diener HC, Bogousslavsky J, Brass LM, et al. Aspirin and clopidogrel compared with clopidogrel alone after recent ischaemic stroke or transient ischaemic attack in high-risk patients (MATCH): randomised, double-blind, placebocontrolled trial. Lancet 2004;364:331-337

57. Hernández AV, Westerhout CM, Steyerberg EW, et al. Effects of platelet glycoprotein IIb/IIIa receptor blockers in non-ST elevation acute coronary syndromes: benefit and harm in different age subgroups. Heart 2007;93:450-455

58. Cho L, Topol EJ, Balog C, et al. Clinical benefit of glycoprotein IIb/IIIa blockade with abciximab is independent of gender: pooled analysis from EPIC, EPILOG and EPISTENT trials. Evaluation of 7E3 for the Prevention of Ischemic Complications. Evaluation in Percutaneous Transluminal Coronary Angioplasty to Improve Long-Term Outcome with Abciximab GP IIb/IIIa blockade. Evaluation of Platelet IIb/IIIa Inhibitor for Stent. J Am Coll Cardiol 2000;36:381-386

59. Alexander KP, Chen AY, Newby LK, et al. Sex differences in major bleeding with glycoprotein IIb/IIIa inhibitors: results from the CRUSADE (Can Rapid risk stratification of 
Unstable angina patients Suppress Adverse outcomes with Early implementation of the ACC/AHA guidelines) initiative. Circulation 2006;114:1380-1387

60. Rasty S, Borzak S, Tisdale JE. Bleeding associated with eptifibatide targeting higher risk patients with acute coronary syndromes: incidence and multivariate risk factors. J Clin Pharmacol 2002;42:1366-1373

61. Kirtane AJ, Piazza G, Murphy SA, et al. Correlates of bleeding events among moderate- to high-risk patients undergoing percutaneous coronary intervention and treated with eptifibatide: observations from the PROTECT-TIMI30 trial. J Am Coll Cardiol 2006;47:2374-2379

62. Alexander KP, Chen AY, Roe MT, et al. Excess dosing of antiplatelet and antithrombin agents in the treatment of nonST-segment elevation acute coronary syndromes. JAMA 2005;294:3108-3116

63. Sabatine MS, Hamdalla HN, Mehta SR, et al. Efficacy and safety of clopidogrel pretreatment before percutaneous coronary intervention with and without glycoprotein IIb/IIIa inhibitor use. Am Heart J 2008;155:910-917

64. Topol EJ, Moliterno DJ, Herrmann HC, et al. Comparison of two platelet glycoprotein IIb/IIIa inhibitors, tirofiban and abciximab, for the prevention of ischemic events with percutaneous coronary revascularization. N Engl J Med 2001;344:1888-1894

65. The NINDS. t-PA Stroke Study Group. Intracerebral hemorrhage after intravenous t-PA therapy for ischemic stroke. Stroke 1997;28:2109-2118

66. Larrue V, von Kummer R, del Zoppo G, Bluhmki E. Hemorrhagic transformation in acute ischemic stroke. Potential contributing factors in the European Cooperative Acute Stroke Study. Stroke 1997;28:957-960

67. Jaillard A, Cornu C, Durieux A, et al. Hemorrhagic transformation in acute ischemic stroke. The MAST-E study. MAST-E Group. Stroke 1999;30:1326-1332

68. Cocho D, Borrell M, Martí-Fàbregas J, et al. Pretreatment hemostatic markers of symptomatic intracerebral hemorrhage in patients treated with tissue plasminogen activator. Stroke 2006;37:996-999

69. Neumann-Haefelin T, Hoelig S, Berkefeld J, et al. Leukoaraiosis is a risk factor for symptomatic intracerebral hemorrhage after thrombolysis for acute stroke. Stroke 2006;37:2463-2466

70. Mielke O, Wardlaw J, Liu M. Thrombolysis (different doses, routes of administration and agents) for acute ischaemic stroke. Cochrane Database Syst Rev 2004;4:CD000514

71. Gurwitz JH, Gore JM, Goldberg RJ, et al. Risk for intracranial hemorrhage after tissue plasminogen activator treatment for acute myocardial infarction. Participants in the National Registry of Myocardial Infarction 2. Ann Intern Med 1998;129:597-604

72. Gore JM, Granger CB, Simoons ML, et al. Stroke after thrombolysis. Mortality and functional outcomes in the GUSTO-I trial. Global Use of Strategies to Open Occluded Coronary Arteries. Circulation 1995;92:2811-2818

73. White HD, Barbash GI, Modan M, et al. After correcting for worse baseline characteristics, women treated with thrombolytic therapy for acute myocardial infarction have the same mortality and morbidity as men except for a higher incidence of hemorrhagic stroke. The Investigators of the International Tissue Plasminogen Activator/Streptokinase Mortality Study. Circulation 1993;88:20972103
74. Simoons ML, Maggioni AP, Knatterud G, et al. Individual risk assessment for intracranial haemorrhage during thrombolytic therapy. Lancet 1993;342:1523-1528

75. Berkowitz SD, Granger CB, Pieper KS, et al. Incidence and predictors of bleeding after contemporary thrombolytic therapy for myocardial infarction. The Global Utilization of Streptokinase and Tissue Plasminogen activator for Occluded coronary arteries (GUSTO) I Investigators. Circulation 1997;95:2508-2516

76. Gruppo Italiano per lo Studio della Sopravivenza nell'Infarto Miocardico (GISSI-2). A factorial randomised trial of alteplase versus streptokinase and heparin versus no heparin among 12,490 patients with acute myocardial infarction. Lancet 1990;336:65-71

77. Third International Study of Infarct Survival- Collaborative Group (ISIS-3). A randomised comparison of streptokinase vs tissue plasminogen inhibitor vs anistreplase and of aspirin plus heparin vs aspirin alone among 41,299 cases of suspected acute myocardial infarction. Lancet 1992;339: 753-770

78. Gore JM, Sloan M, Price TR, et al. Intracerebral hemorrhage, cerebral infarction, and subdural hematoma after acute myocardial infarction and thrombolytic therapy in the Thrombolysis in Myocardial Infarction Study. Thrombolysis in Myocardial Infarction, Phase II pilot and clinical trial. Circulation 1991;83:448-459

79. Van de Werf F, Barron HV, Armstrong PW, et al. Incidence and predictors of bleeding events after fibrinolytic therapy with fibrin-specific agents: a comparison of TNK-tPA and rt-PA. Eur Heart J 2001;22:2253-2261

80. Cannon CP, Gibson CM, McCabe $\mathrm{CH}$, et al. TNK-tissue plasminogen activator compared with front-loaded alteplase in acute myocardial infarction: results of the TIMI 10B trial. Thrombolysis in Myocardial Infarction (TIMI) 10B Investigators. Circulation 1998;98:2805-2814

81. ISIS-2 (Second International Study of Infarct Survival) Collaborative Group. Randomised trial of intravenous streptokinase, oral aspirin, both, or neither among 17,187 cases of suspected acute myocardial infarction: ISIS-2. Lancet 1988;2:349-360

82. Bouzamondo A, Damy T, Montalescot G, Lechat P. Revascularization strategies in acute myocardial infarction: a meta-analysis. Int J Clin Pharmacol Ther 2004;42:663671

83. Beyth RJ, Quinn LM, Landefeld CS. Prospective evaluation of an index for predicting the risk of major bleeding in outpatients treated with warfarin. Am J Med 1998;105: 91-99

84. Shireman TI, Mahnken JD, Howard PA, et al. Development of a contemporary bleeding risk model for elderly warfarin recipients. Chest 2006;130:1390-1396

85. Gage BF, Yan Y, Milligan PE, et al. Clinical classification schemes for predicting hemorrhage: results from the National Registry of Atrial Fibrillation (NRAF). Am Heart J 2006; 151:713-719

86. Landefeld CS, Cook EF, Flatley M, Weisberg M, Goldman L. Identification and preliminary validation of predictors of major bleeding in hospitalized patients starting anticoagulant therapy. Am J Med 1987;82:703-713

87. Nieuwenhuis HK, Albada J, Banga JD, Sixma JJ. Identification of risk factors for bleeding during treatment of acute venous thromboembolism with heparin or low molecular weight heparin. Blood 1991;78:2337-2343 
88. Landefeld CS, Goldman L. Major bleeding in outpatients treated with warfarin: incidence and prediction by factors known at the start of outpatient therapy. Am J Med 1989; 87:144-152

89. Wells PS, Forgie MA, Simms M, et al. The Outpatient Bleeding Risk Index. Validation of a tool for predicting bleeding rates in patients treated for deep venous thrombosis and pulmonary embolism. Arch Intern Med 2003;163:917-920

90. Aspinall SL, DeSanzo BE, Trilli LE, Good CB. Bleeding risk index in an anticoagulation clinic. Assessment by indication and implications for care. J Gen Intern Med 2005;20:1008-1013
91. Kuijer PM, Hutten BA, Prins MH, Büller HR. Prediction of the risk of bleeding during anticoagulant treatment for venous thromboembolism. Arch Intern Med 1999;159: 457-460

92. Landefeld CS, McGuire EIII, Rosenblatt MW. A bleeding risk index for estimating the probability of major bleeding in hospitalized patients starting anticoagulant therapy. Am J Med 1990;89:569-578

93. Wells PS, Anderson DR, Rodger MA, et al. A randomized trial comparing 2 low-molecular-weight heparins for the outpatient treatment of deep vein thrombosis and pulmonary embolism. Arch Intern Med 2005;165:733-738 